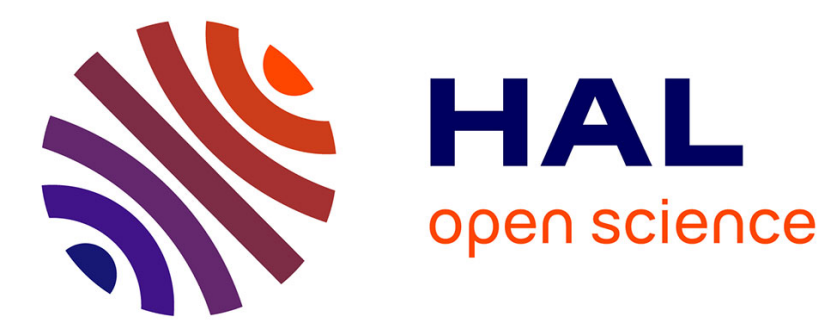

\title{
Ferrite Electromagnetic Wave Absorbers
}

\author{
Y. Naito
}

\section{To cite this version:}

Y. Naito. Ferrite Electromagnetic Wave Absorbers. Journal de Physique IV Proceedings, 1997, 07

(C1), pp.C1-405-C1-408. 10.1051/jp4:19971164 . jpa-00254810

\section{HAL Id: jpa-00254810 https://hal.science/jpa-00254810}

Submitted on 1 Jan 1997

HAL is a multi-disciplinary open access archive for the deposit and dissemination of scientific research documents, whether they are published or not. The documents may come from teaching and research institutions in France or abroad, or from public or private research centers.
L'archive ouverte pluridisciplinaire HAL, est destinée au dépôt et à la diffusion de documents scientifiques de niveau recherche, publiés ou non, émanant des établissements d'enseignement et de recherche français ou étrangers, des laboratoires publics ou privés. 


\title{
Ferrite Electromagnetic Wave Absorbers
}

\author{
Y. Naito
}

Department of Physical Electronics, Tokyo Institute of Technology, 2-12-1 Ookayama, Meguro-ku, Tokyo 152, Japan

\begin{abstract}
The necessity of the electromagnetic wave absorbers is becoming larger and larger. After World War II, absorbers in microwave frequencies were necessary to develop microwave technology. Now it is a digital age. So from low frequency up to high frequency there are a lot of leakage electromagnetic waves. Let say from $30 \mathrm{MHz}$ up to $1000 \mathrm{MHz}$. To absorb from $30 \mathrm{MHz}$ up to $1000 \mathrm{M} H z$ with thin and cheap absorber is strongly wanted.

Also, the absorbers which can absorb from $30 \mathrm{MHz}$ to $60 \mathrm{GHz}$, for example, are asked to be designed with very thin thickness. In this paper,firstly overview about absorbers will be given and secondary the present status of the art will follow.
\end{abstract}

\section{Electromagnetic Wave Absorbers}

The title of this paper is FERRITE ELECTROMAGNETIC WAVE ABSORBERS. But the author considers it is better to give first a short general explanation about absorbers.
1.1 Material
(i) Carbon (Conduction loss $\sigma$ )
(ii) Ferrite (Magnetic loss $\mu^{\prime \prime}$ )
(iii) Ferroelectric Material (Dielectric Joss E")
(iv) Combination of the above

\subsection{Characteristics of Absorber}

(i) Value of Reflection

In many cases a power reflexion less than $1 \%$ is permitted. That means that the absorption should be better than $99 \%$. According to the needs, the value will be adapted.

(ii) Frequency Characteristics

Frequency characteristics of reflection is very important for practical use. Two kinds of characteristics are defined. One is $N$ type and the other is $W$ type. There are shown in Fig. 1 (a) and (b), respectively. $N$ type means in certain frequency band ( from $f_{1}$ to $f_{l_{2}}$ ), the reflection in less than permissible value $S_{0}$. The typical application of the $N$ type is to prevent the TV signal reflection from the walls of buildings. In Japan they are sometimes being used. W type means the reflection is less than permissible value $S_{0}$ from $f_{l}$ up to infinity theoretically. 


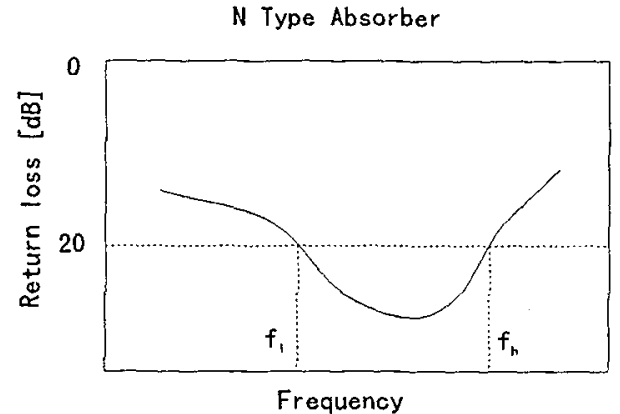

(a)

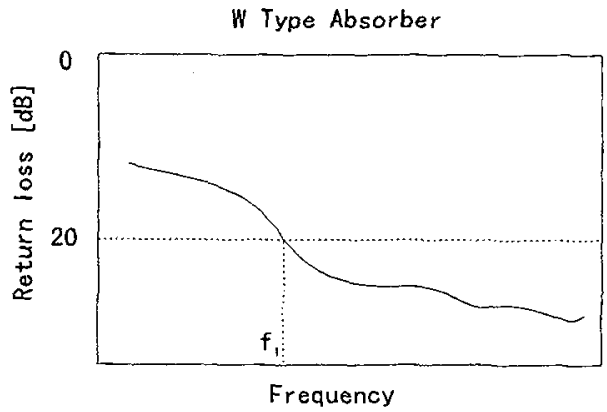

(b)

Fig. 1 Characteristics of Absorber's Type

(iii) Thickness

When we make an electromagnetic wave dark room, the size itself will be determined from the purpose of use of the room. Let's say $3 \mathrm{~m}$ measurement or $10 \mathrm{~m}$ measurement. So if we can design the absorber thickness as thin as possible, then, the needed absorber materials become as small as possible, which finally brings the cost down. In such a sense, the thickness needed is very important.

(iv) Weight

(v) Oblique incidence characteristics

(vi) Price

\subsection{Application}

(i) For dark room

(ii) Antireflection walls and sheet for buildings and bridge

(iii) Unwanted resonance elimination in electronics devices or dark rooms

\section{Proposed Absorbers}

So far several proposals have been done. I will show them, in Fig. 2.

\section{Characteristics of Proposed Absorbers}

\section{(1) Single layer (contains Carbon Powder) N type}

Thickness can be controlled by the kind of rubber and the amount of carbon, but generally speaking the bandwidth is narrow This absorber is useful above $X$ band. With the increase of the number of layers, characteristics are improved but the thickness becomes large.

\section{(2) Pyramidal Absorber W type}

This is the most widely used type in the world. W type can be made easily. The absorber the characteristics of which are less than $1 \%$ reflection from $30 \mathrm{MHz}$ up to infinity will be constructed with a thickness of about $4 \mathrm{~m}$.

\section{(3) Single layer ( Rubber containing Ferrite Powder) N type}

Originally this type was tested at $\mathrm{X}$ band a long time ago. The matcling frequency $\mathrm{f}_{\mathrm{m}}$ is from $400 \mathrm{MHz}$ to $5000 \mathrm{MHz}$. The thickness is about $6 \sim 8 \mathrm{~mm}$, regardless of the $f_{\mathrm{m}}$. Bandwidth is wider than (1) but narrower than (4). [1] 


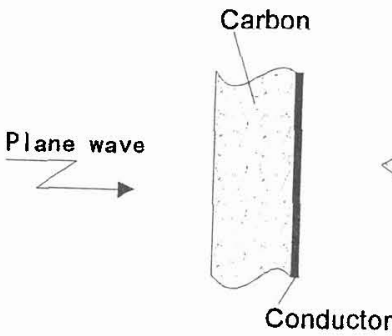

(1)

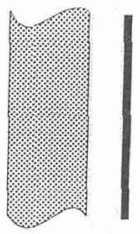

(5)

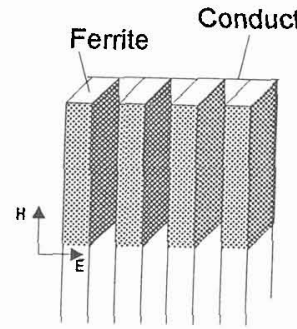

(8)

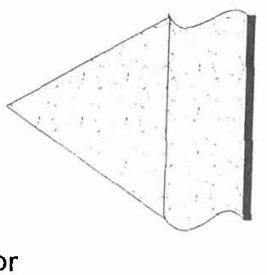

(2)
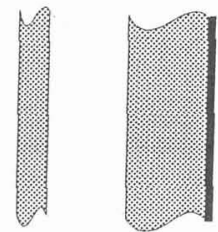

(6)

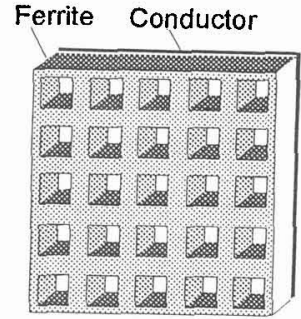

(9)

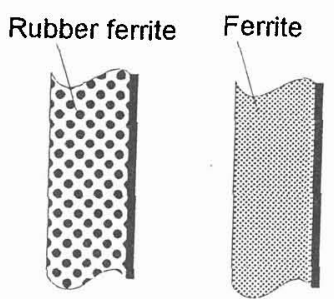

(3)

(4)

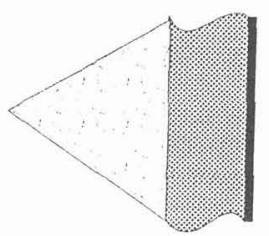

(7)

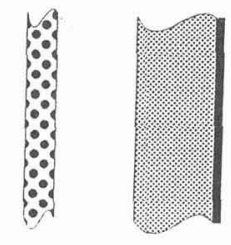

(10)

Fig. 2 Many Proposed Absorbers 
(4), (5) and (6)

These three types of absorber were proposed by Dr. H.W. Helberg et al in 1960, 1963 and 1965 respectively[2][3]. (4) and (5) are now widely being used. All are $\mathrm{N}$ type and when $\mathrm{fl}=30 \mathrm{MHz} \mathrm{f}_{\mathrm{l}}$ are $400 \mathrm{MHz}, 700 \mathrm{MHz}, 2000 \mathrm{MHz}$ respectively. Ferrite thicknesses are about $6 \sim 8 \mathrm{~mm}$. In case of (6), the number of ferrite sheets is $x 2$ and so it becomes expensive.

\section{(7) Composite Absorber}

This was proposed by the author in 1967. The characteristics are the same as (2) but the thickness is about $1 \mathrm{~m}$. This is now being used widely for EMC measurement room and is shorter than that of (2).

\section{(8) Fin absorber}

This is designed for one polarization. (4) can be used to absorb TV signal in VHF but (8) can absorb not only VHF but also UHF. It can work from $30 \mathrm{MHz} \sim 2000 \mathrm{MHz}$. [4]

\section{(9) Grid absorber}

Vertical Fin and Horizontal Fin are put in one structure. This can work in the range 30MHz $\sim 800 \mathrm{MHz}$ with less then $1 \%$ reflection. This is now becoming very popular for EMC chamber, because thickness needed is only $19 \mathrm{~mm}$. It is the thinnest structure in the world. [5]

\section{(10) Improved version of (6)}

As already mentioned, (6) are expensive because of double number of Ferrite sheet. With a good design, the front ferrite ( Sintered) can be replaced by Rubber Ferrite. It brings the price less expensive and this can work from $30 \mathrm{MHz}$ to $1400 \mathrm{MHz}$.

\section{References}

[1] Y.Naito and K.Suetake.,"Applicaion of Ferrite to Electromagnetic Wave Absorber and Its Characteristics".IEEE Transactons on Microwave theory and Techniques, January 1971 pp.65-72.

[2] H. -W. Helberg, "Die Absorption elektromagnetischer Wellen in einem groben Frequenzbereich durch eine dunne homogene Schicht mit Verlusten", Zeitschrift fur angewandte Physik, vol.5, pp.237-245, 1961.

[3] H. -W. Helberg and V. Kose, "Die Breitbandige Absorption elektromagnetischer Wellen durch dunner Ferritschichten", Zeitschrift fur angewandte Physik, vol.19, pp.509-514, 1965.

[4] Y.Naito and H.Anzai and T.Mizumoto,"Ferrite Grid Electromagnetic Wave Absorbers", Technical Digest of IEEE International Sympposium on EMC, pp.254-259, 1993 Dallas.

[5] Y.Naito and T.Mizumoto,"Anechoic Chamber Having Multi-Layer Sintered Ferrite and Ferrite Composite Membrane", Technical Digest of IEEE International Sympposium on EMC, pp.402-407, 1994 Chicago. 